\title{
Effect of dispersity of powder system Al-Mg-B on the phase composition of sintered ceramics $\mathrm{AlMgB}_{14}$
}

\author{
Pavel Nikitin ${ }^{1}$, Ilya Zhukov ${ }^{1}$, Alexander Vorozhtsov ${ }^{1,2}$, Alexander Zhukov ${ }^{1}$, and Yana Dubkova ${ }^{1, *}$ \\ ${ }^{1}$ National Research Tomsk State University, Tomsk, 634050, Russia \\ ${ }^{2}$ Institute for Problems of Chemical \& Energetic Technologies of the SB RAS, Biysk, 659322, Russia
}

\begin{abstract}
In work studies of materials obtained from various powder mixtures $\mathrm{Al}-\mathrm{Mg}-\mathrm{B}$ after mechanical processing in a planetary mill and subsequent vacuum sintering were carry out. It was found that for each mixture exists optimal time of mechanical treatment in a planetary mill, at which the maximum content of $\mathrm{AlMgB}_{14}$-phase is reached. It was shown that for the samples synthesized from the $\mathrm{Al}-\mathrm{Mg}-\mathrm{B}$ powder mixture with the dispersion of the raw aluminium powder $<\mathrm{d}>\sim 80 \mu \mathrm{m}$ after 5 hours of mechanical activation and subsequent vacuum sintering at a temperature of $1130{ }^{\circ} \mathrm{C}$, the maximum phase of $\mathrm{AlMgB}_{14}$ is $\sim 85-90$ wt. $\%$.
\end{abstract}

\section{Introduction}

The constant development of technology and industry necessitates the introduction of new materials, having high physical and mechanical properties. Borides are one such materials. Currently, borides can be used as high energy materials and reinforcing elements, they have high heat resistance and the ability to withstand constant loads [1]. One of the most promising materials in this category is material based on ternary compound of aluminium, magnesium and boron - $\mathrm{AlMgB}_{14}$ due to high hardness, reaching $46 \mathrm{GPa}$ with addition of $\mathrm{TiB}_{2}$, friction coefficient, reaching of amount $\sim 0.02[2-3]$ and coefficient of thermal expansion (CTE) $\sim 9\left(10^{-6}\right) \mathrm{K}^{-1}$, which is close to the coefficient of thermal expansion of steels $\sim 11\left(10^{-6}\right) \mathrm{K}^{-1}$ [4-5]. The foregoing shows an opportunity of the using materials $\mathrm{AlMgB}_{14}$ as wearresistant materials and coatings. Usually, methods of metal powder industry (field-activated pressure-assisted synthesis (FAPAS), spark plasma sintering (SPS), reactive SPS (R-SPS), pressing and subsequent vacuum sintering [6-8], etc.) are used to produce of $\mathrm{AlMgB}_{14}$ [9-13]. Mechanical activation (MA), allowing to increase reactive capability of powder mixtures, can used to intensification of produce. The main problem of obtaining the materials based on $\mathrm{AlMgB}_{14}$ is contamination with impurity phases, associated with the oxidation of the raw powders of aluminum, magnesium and boron. Despite this problem, there is insufficient information in the literature on the effect of the dispersion of the raw aluminum, magnesium, and boron powders on the phase composition of products obtained from these powders [14-16]. The purpose of this work is to study the phase composition of materials obtained from various powder mixtures Al-Mg-B after mechanical activation and subsequent vacuum sintering.

\section{Methods and materials}

Powders of magnesium (particle size $<\mathrm{d}>\sim 100 \mu \mathrm{m}$ ), amorphous black boron with particle size of $1 \mu \mathrm{m}$ were used as raw powders. Powders with average particle size $<\mathrm{d}>\sim 4 \mu \mathrm{m},<\mathrm{d}>\sim 10 \mu \mathrm{m}$ and $<\mathrm{d}>\sim 80 \mu \mathrm{m}$ were used as raw powders of aluminum. Powders of $\mathrm{Al}: \mathrm{Mg}: \mathrm{B}$ were mixed in an atomic ratio 1:1:14 (Table 1):

Table 1. Average particle size of raw powders.

\begin{tabular}{|c|c|c|c|}
\hline Mixture & $\begin{array}{c}<\mathrm{d}>_{\text {particles }} \\
\mathrm{Al}\end{array}$ & $\begin{array}{c}<\mathrm{d}>_{\text {particles }} \\
\mathrm{Mg}\end{array}$ & $\begin{array}{c}<\mathrm{d}>_{\text {particles }} \\
\mathrm{B}\end{array}$ \\
\hline A1. & $4 \mu \mathrm{m}$ & & \\
\cline { 1 - 2 } $\mathrm{A} 2$. & $10 \mu \mathrm{m}$ & \multirow{2}{*}{$100 \mu \mathrm{m}$} & $1 \mu \mathrm{m}$ \\
\hline A3. & $80 \mu \mathrm{m}$ & & \\
\hline
\end{tabular}

The resulting powder mixtures underwent mechanical activation in a planetary mill. The ratio of milling ball to the powder charge was 2:1. The processing time ranged from 1 to 5 hours under a load of 40G. Mechanical activation was carried out in an argon atmosphere with preliminary evacuation of the working space. The particle size in powders was determined using the analyzer ANALYSETTE 22 MicroTec plus. Calorimetric studies were performed using a thermal analyser «Mettler Toledo» (module TGA / SDTA 851). The morphology of Al-Mg-B powders was studied using a scanning electron microscope Philips SEM 515. From the obtained powder mixtures, the samples were pressed with a diameter of $10 \mathrm{~mm}$ in steel press-form under pressure $130 \mathrm{MPa}$. Samples were sintered in a vacuum

* Corresponding author: y.a.dubkova@niipmm.tsu.ru 
combustor Nabertherm VHT 8/22-GR. XRD analysis was performed using a Shimadzu XRD-6000 diffractometer with $\mathrm{CuK} \alpha$ radiation.

\section{Results and discussions}

\subsection{Particle size}

The dependence of average particle size of obtained powder mixtures on the processing time in a planetary mill for A1, A2, A3 powder mixtures is shown in Figure 1.

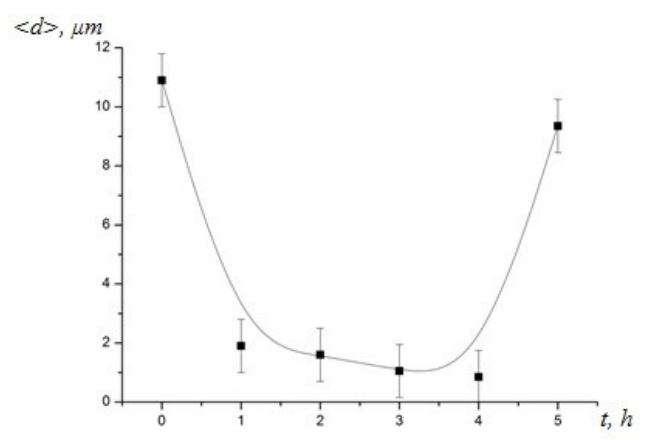

a

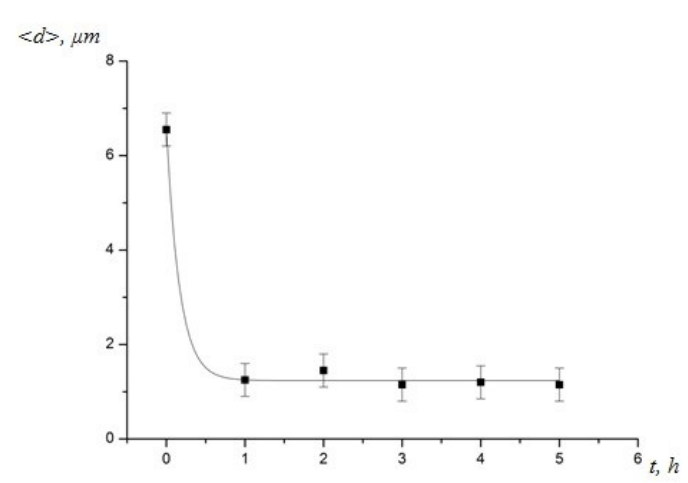

$\mathrm{b}$

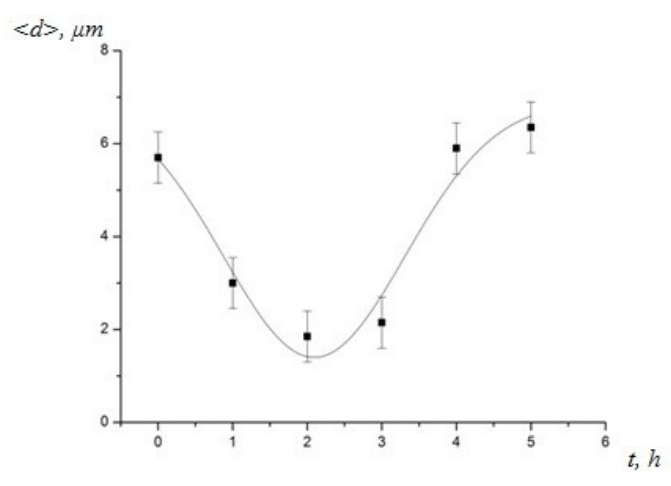

c

Fig. 1. The dependence of average particle size on processing time for (a) - A2, (b) - A3, (c) - A1 powder mixtures.

Figure 1 shows that the average particle size of A2 powder mixture after 1 hour of mechanical activation decreases from $11 \mu \mathrm{m}$ to $2 \mu \mathrm{m}$. A minimum particle size of $0.8 \mu \mathrm{m}$ is observed at 4 hours of mechanical activation. After 5 hours of mechanical activation, a sharp increase in average particle size from 0.8 to 9.3 $\mu \mathrm{m}$ is observed. For A3 mixture after 1 hours of processing in a planetary mill, the average particle size decreases from $7 \mu \mathrm{m}$ to $1.6 \mu \mathrm{m}$ and then doesn't change. The minimum particle size for A1 mixture corresponds to a 2-hour of mechanical activation and is $1.9 \mu \mathrm{m}$, further processing results to a sharp increase in the average particle size from $1.9 \mu \mathrm{m}$ to $6.2 \mu \mathrm{m}$ at 5 hours of mechanical activation.

\subsection{DSC}

The results of differential scanning calorimetry (DSC) of A1 powder mixture are shown in the Figure 2.

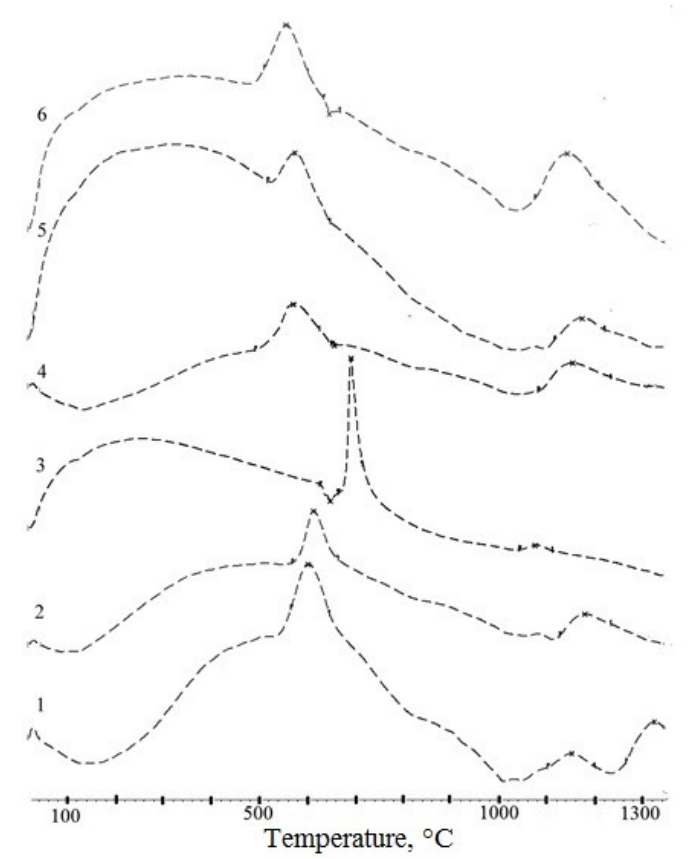

Fig. 2. DSC-patterns of Al powder mixtures before (1) and after mechanical activation: $2-1$ hour, $3-2$ hours, $4-3$ hours, $5-4$ hours, $6-5$ hours.

It can be seen from Figure 2 that exothermic peaks are observed in the temperature range of $500-700{ }^{\circ} \mathrm{C}$ and $1150-1250{ }^{\circ} \mathrm{C}$. The displacement of the first exothermic peak into the region of lower temperatures with increasing time of mechanical activation is due to an increase in the reactivity of the mixture. With a further increase in temperature, aluminum and magnesium particles melt. The presence of small endothermic peaks is probably due to the melting of aluminum particles not reacted due to a dense oxide film.

Based on the obtained thermograms, two-stage heat treatment conditions for the Al-Mg-B mixture for the synthesis of $\mathrm{AlMgB}_{14}$ were selected. In the first stage, the mixture of $\mathrm{Al}-\mathrm{Mg}-\mathrm{B}$ was heated to $550{ }^{\circ} \mathrm{C}$ with an exposure time of 0.5 hours. Then, heating was carried out to temperatures of $1130{ }^{\circ} \mathrm{C}$ and $1300{ }^{\circ} \mathrm{C}$, respectively, with an exposure time of 1 hour. 


\subsection{XRD}

XRD-patterns of samples sintered at $1130{ }^{\circ} \mathrm{C}$ from powder mixtures A2 before and after mechanical activation are shown in Figure 3.

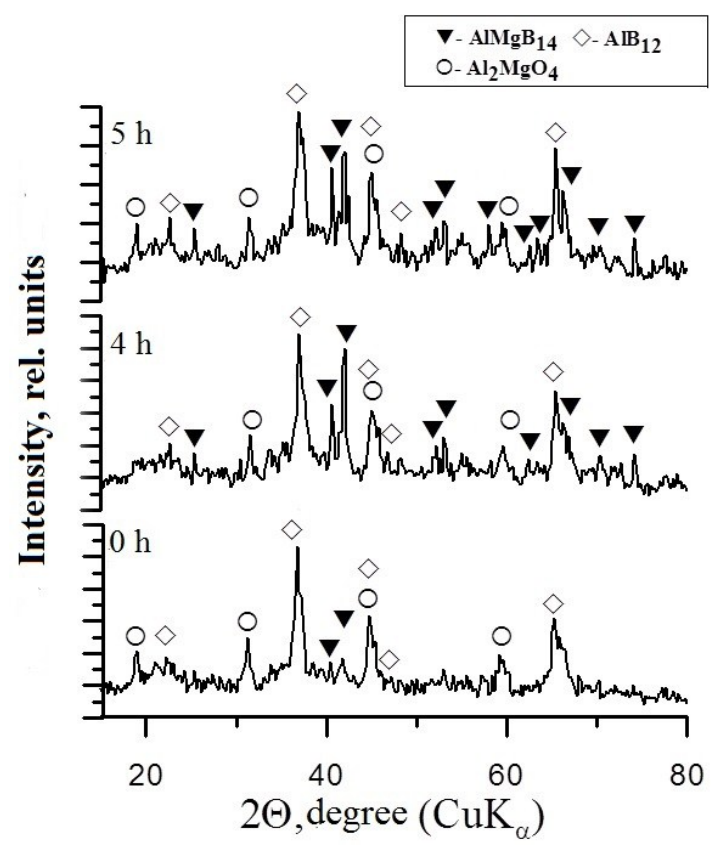

Fig. 3. The effect of mechanical activation time of A2 powder mixture on phase composition of obtained products, sintered at a temperature $1130{ }^{\circ} \mathrm{C}$.

On all XRD-patterns, it is possible to identify the phase of $\mathrm{AlMgB}_{14}$. Approximate phase content of $\mathrm{AlMgB}_{14}$ was calculated from the intensity ratio of the peaks. The maximum phase content of $\mathrm{AlMgB}_{14}$ is found at 4 hours of mechanical activation and is $70-75$ wt. $\%$. After 5 hours of mechanical activation the content of $\mathrm{AlMgB}_{14}$ is reduced from $70-75 \mathrm{wt} \%$ to $56 \mathrm{wt} \%$.

A sharp increase in the average particle size in A2 powder mixture after 5 hours of mechanical activation is probably due to agglomeration of nanosized particles under Van-der-Waals forces. The formation of conglomerates complicates the formation of complex boride compounds. In agglomeration of particles, apparently, the number of neighbours decreased to add boron and, respectively, to form borides.

SEM-image of A1 powder mixture after 5 hours mechanical activation and an XRD-pattern of the sample, obtained from this powder mixture and sintered at the temperature of $1300^{\circ} \mathrm{C}$, are shown in Figure 4.
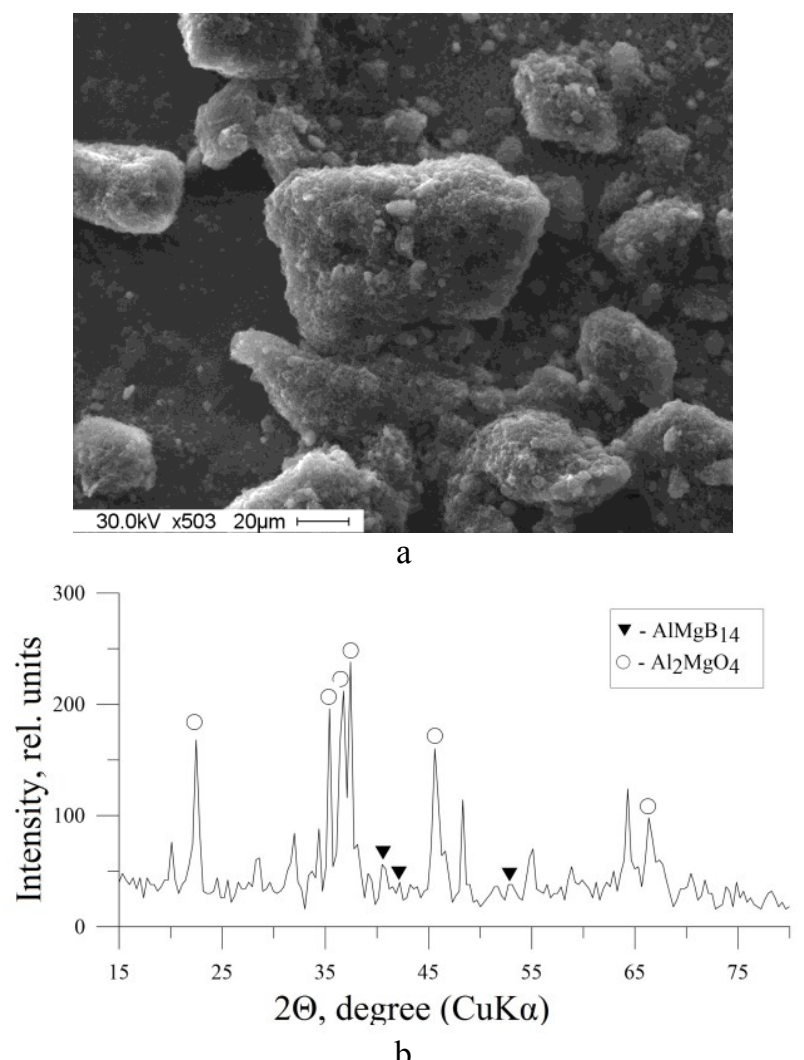

Fig. 4. SEM-image of A1 powder system after 5 hours mechanical activation (a) and XRD-pattern of sample, sintered at the temperature of $1300^{\circ} \mathrm{C}$ from this powder mixture (b).

Figure 4 shows that the A1 powder mixture after 5 hours mechanical activation is represented mainly by large agglomerates, apparently consisting of nanosized aluminum and magnesium particles. Wherein, the phase composition of sintered from this mixture products is represented a large quantity of the impurity phase with a complex crystal lattices $\left(\mathrm{MgAl}_{2} \mathrm{O}_{4}, \mathrm{AlB}_{12}, \mathrm{AlB}_{2}, \mathrm{Al}_{2} \mathrm{O}_{3}\right.$ et al.). This makes it difficult the determine of real picture in view on the fact that on XRD-pattern (3b) these phases are located at the same angle of diffraction, so it was not possible to identify the majority of peaks.

A large number of impurity oxide phases for the samples sintered from A1 powder mixtures (with an aluminum dispersion $<\mathrm{d}>\sim 4 \mu \mathrm{m}$ ), after 5 hours of mechanical activation is apparently related to the difference in the nature of the oxidation of the raw aluminium and magnesium powders and, respectively, due to the formation of strong oxide films, which impede the formation of the intermediate boride phase $\mathrm{AlMgB}_{4}$ [6-8].

Possibly, for aluminium powders with an average particle size $<\mathrm{d}>\sim 4 \mu \mathrm{m}$ strength of films and content of oxide is significant higher than for aluminium powders with $<\mathrm{d}>\sim 10 \mu \mathrm{m}$ (mixture A2) and $<\mathrm{d}>\sim 80 \mu \mathrm{m}$ (mixture A3).

XRD-pattern of the sample, obtained from A3 powder mixture after 5 hours mechanical activation and sintered at the temperature of $1130{ }^{\circ} \mathrm{C}$, is shown in Figure 5. 


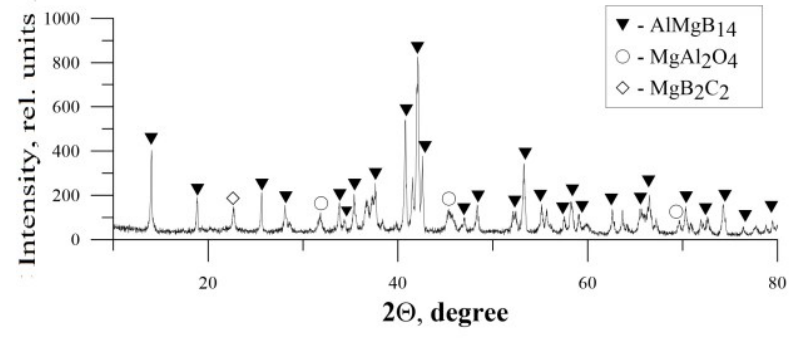

Fig. 5. XRD of sample obtained from A3 powder mixture after 5 hours mechanical activation and sintered at the temperature of $1130^{\circ} \mathrm{C}$.

The phase composition is mainly represented by the boride phase of $\mathrm{AlMgB}_{14} \sim 85-90 \%$ with the content of impurities $\mathrm{MgAl}_{2} \mathrm{O}_{4}$ и $\mathrm{MgB}_{2} \mathrm{C}_{2}$ not more than $15 \mathrm{wt}$. \%.

Apparently, the formation of the spinel phase $\mathrm{MgAl}_{2} \mathrm{O}_{4}$ is related to the oxidation of raw boron powder: during the sintering at a temperature of $600-800{ }^{\circ} \mathrm{C}$ oxygen released from the boron powder reacts with magnesium and aluminum powders and leads to formation of the spinel phase. The formation of $\mathrm{MgB}_{2} \mathrm{C}_{2}$ phase is apparently related to the diffusion between graphite thermal element of combustor and the samples.

\section{Conclusion}

In conclusion, the regularities of forming phase composition of materials based on $\mathrm{AlMgB}_{14}$ were studied. It was found that the optimal time at which it is possible to obtain the maximum phase of $\mathrm{AlMgB}_{14}$ exists for each powder mixture and depends to the average particle size of raw Al powders. It was shown that maximum phase content of $\mathrm{AlMgB}_{14}$ is $85-90 \mathrm{wt}$. \% for the sample sintered at a temperature of $1130^{\circ} \mathrm{C}$ from $\mathrm{A} 3$ powder mixture $\left(<\mathrm{d}>_{\mathrm{Al}} \sim 80 \mu \mathrm{m}\right)$ after 5 hours mechanical activation. The phase content of $\mathrm{AlMgB}_{14}$ is 75 wt. $\%$ for sample sintered at a temperature of $1130^{\circ} \mathrm{C}$ from $\mathrm{A} 2$ powder mixture $(<\mathrm{d}>\mathrm{Al} \sim 10 \mu \mathrm{m})$ after 4 hours of mechanical activation. Further mechanical activation leads to a decrease in $\mathrm{AlMgB}_{14}$-phase from 75 to $56 \mathrm{wt} . \%$. This is probably due to the agglomeration of nanosized particles under the action of Van-der-Waals forces and the formation of thin oxide films which impede the formation of the intermediate boride phase $\mathrm{AlMgB}_{4}$. Further studies are aimed at studying the effect of the phase composition on the structure and physicmechanical properties of the resulting materials.

Studies were funded by Russia Science Foundation (project No. 17-79-10272).

\section{References}

1. A.S. Zhukov, I.A. Zhukov, M.X. Ziatdinov, V.V. Promaxov, A.B. Vorozhtsov, S.A. Vorozhtsov, Ya.A. Dubkova, AIP Conf. Proc., 1772, 020015-1020015-4 (2006)

2. B. Cook et al. Scripta Mater., 42, 597-602 (2000)
3. J. Chen et al. Ceramics International, 43, 1236212371 (2017)

4. A. H. Shaw, Graduate Theses and Dissertations (Iowa State University, 2011)

5. A. M. Russel et al. Scripta Mater., 46, 629-633 (2002)

6. V.F. Komarov, M.V. Komarova, A.B. Vorozhtsov, M.I. Lerner, Russian Physics Journal, 55, 13-18 (2012)

7. D.J. Roberts, J. Zhao, Z. A. Munir, Int. Journal of Refractory Metals and Hard Materials, 27, 556-563 (2009)

8. Z. Xie, V. DeLucca, R.A. Haber, D.T. Restrepo, J. Todd, R.G. Blair, N. Orlovskaya, Advances in applied ceramics, 116 (6), 341-347 (2017)

9. Shota Miura et al. Journal of Physics and Chemistry of Solids. 75 (8), 951-953 (2014)

10. Wen Liu et al. J. Mater. Sci. Technol., 29 (1), 77-81 (2013)

11. V.I. Ivashchenko et al. Journal of Applied Physics, 119, 205105 (2016)

12. V. Kevorkijan et al. Metall. Mater. Eng., 21 (1), $45-$ 55 (2015)

13. D.V.S. Muthu, B. Chen, B.A. Cook, M.B. Kruger, High Pressure Research, 28 (1), 63-68 (2008)

14. I.A. Zhukov, M.X. Ziatdinov, Ya.A. Dubkova, P.Yu. Nikitin, Russian Physics Journal (to be published)

15. P. Yu. Nikitin, I.A. Zhukov, Ya.A. Dubkova, Proceedings of the $56^{\text {th }}$ International Students Scientific Conference, 179 (Novosibirsk, 2018)

16. P. Yu. Nikitin, I.A. Zhukov, Ya.A. Dubkova, Prospects of fundamental sciences development. XV International Conference of students, graduate students and young scientists (to be published) 